\title{
Antimicrobial potential of eucalyptus oil and lemongrass oil alone and in combination against clinical bacteria in
} planktonic and biofilm mode

\section{Iram Liaqat, Amna Asgar}

Microbiology Lab, Department of Zoology, GC University, Lahore, Pakistan

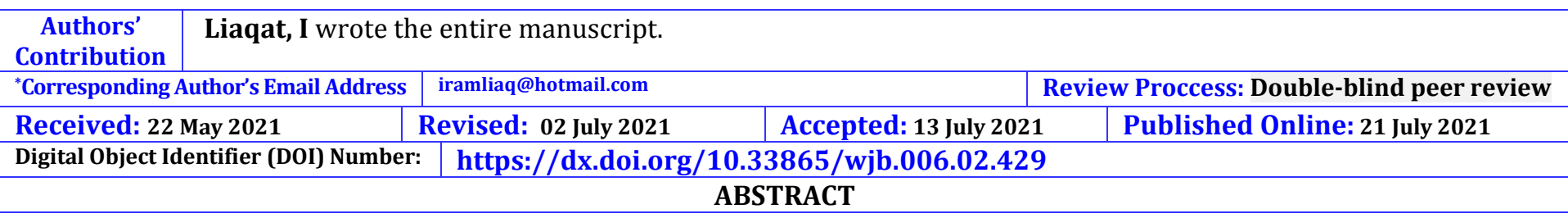

The use of natural substances has been trending for past few years. In recent years, synthetic products obtained from plants have gained immense importance. Essential oils and volatile products obtained from plants are the sources of food flavoring, aroma products, and fragrance industries. Their use is also common to cure different ailments such as cancer, skin problems, and nosocomial infections. Vast research has shown the antimicrobial properties of essential oils obtained from plants. Essential oils of lemongrass and eucalyptus have antiviral, antibacterial, antioxidant, and insecticidal characteristics. Lemongrass and eucalyptus oils show their antibacterial activity towards Gram-positive bacteria such as Staphylococcus aureus, Bacillus subtilis, and Gram-negative bacteria such as Escherichia coli and Klebsiella pneumonia. The combination of these oils also depicts high antimicrobial activity against different strains of bacteria. This review highlights the use of essential oils of lemongrass and eucalyptus for their in vitro antimicrobial properties against different bacteria in planktonic and biofilm mode. Mode of action by which the oil shows its inhibitory activity will be discussed. Susceptibility shown by different bacteria towards these essential oils and their components will be described.

\section{Keywords: Antimicrobial activity, antibiofilm activity, eucalyptus oil, lemongrass oil, mode of action.}

INTRODUCTION: Medicinal plants are one of the most important sources of traditional medicines which are being used by the whole world. Nowadays, medicinal research has shown the importance of herbal remedies since these are the active means of bioactive compounds (Moosavy and Shavisi, 2013). Volatile oils also called essential oils are derived from plant husk, buds, barks, wood, seeds, leaves, flowers, twigs, herbs, roots and fruit, and aromatic oily liquids. There is an estimation of about 2500-3000 volatile oils; in the fragrance market which are commercially important (Boyanova et al., 2005). Essential oils have antiviral, antibacterial, antioxidant, and insecticidal characteristics. Additionally, the use of these oils in cancer treatment is also common. Lemongrass and eucalyptus are very well-known fragrant herbal plants. Lemongrass belongs to the Poaceae family and is cultivated in tropical and subtropical regions of the world. It is widely popular in Asian cuisine and medicinal practices for its aroma, active ingredients and health benefits (Santin et al., 2009). The Eucalyptus plant belongs to the family Myrtaceae. It was originally used in Australia but is now commonly found throughout the world. It is a large genus and has about 900 types and subtypes. Dried leaves and hot water extracts of eucalyptus (lemon-scented eucalyptus) are used in analgesic, anti-inflammatory, and antipyretic treatments for the indication of respiratory inflammation, like sinus congestion, cold, and flu and cure for many other diseases (Silva et al., 2003).

Lemongrass and eucalyptus plants have essential oils that are evaporative, intensive, and deliquescent liquids with nice and strong odors (Babayi et al., 2004). These oils are used in food preservatives, the fragrance industry, and aromatherapy (Boyanova et al., 2005). Lemongrass oil is one of the most widely used ingredients for its health benefits (Rauber et al.,
2005). Bioactive compounds present in this oil are utilized mainly for therapeutic motives and the treatment of different ailments (Oloyede, 2009). Eucalyptus oil also acts as an antioxidant and anticancer agent. Eucalyptus globulus and E. radiata essential oils are in great demand, as they are utilized for expectorant, astringent, febrifuge, fumigant, antiseptic, anesthetic, deodorant, inhalant, insect repellant, and abscess disinfectant. Furthermore, its use for folk remedies, wounds, arthritis, burns, boils, asthma, bronchitis, flu, inflammation, worms, and rhinitis is also common (Bachir and Benali, 2012). Bacterial resistance has become a major problem in the field of medicine and has developed due to the continuous use of antibiotics. The development of new chemicals and drugs against bacteria is very necessary (Lokhande et al., 2007). Due to resistance against antibiotics, medicines, and drugs derived from plants are being tested to check their effectiveness against different bacteria especially multi-drug resistant pathogens (Mulyaningsih et al., 2011). The phytochemical compounds in essential oils can act synergistically along with other antimicrobial compounds to eliminate the resistance problem (Chaves et al., 2016; Cristo et al., 2016; Morais-Braga et al., 2016).

Biofilm formed by bacteria is another major concern in the medical sector. Biofilm is the association of bacteria that attach themselves to a surface and form an extracellular matrix to attach. This forms a multicellular association that is highly resistant against antibiotics (Singh et al., 2017). Biofilm is a major cause of the development of diseases for example in patients suffering from diabetes and endocarditis (Thwaites et al., 2011). There are many pieces of evidence regarding the effect of plant essential oils on bacteria but much less is known about their effects on their biofilm-forming ability (Kavanaugh 
et al., 2012).

OBJECTIVES: This review will summarize information on the antimicrobial effect of eucalyptus oil and lemongrass oil and their combined effect from previous researches and studies. The effect on Gram-positive and Gram-negative bacteria in planktonic and biofilm forms is being discussed to understand their antimicrobial potential to improve and promote their use as a medicinal compound in pharmaceutical industries and cosmetics.

Effect of eucalyptus oil on Gram-positive and Gramnegative bacteria: Essential oil of eucalyptus is widely used as an antibacterial agent. Its antimicrobial action mainly depends on its chemical constituents. The major component of eucalyptus oil is terpene 1, 8-cineole also called eucalyptol. Compounds have functional groups such as 1,8-cineole, but terpineol is a major subsidizer for activity since it proved to have 8 times more effective compared to 1,8-cineole against $S$. aureus. Essential oils are extracted from many species of eucalyptus plant, for example, Eucalyptus camaldulensis, E. radiata and E. citriodora are used to obtain oil but commercially available essential oil is extracted from E. globulus (Silva et al., 2003). E. globulus oil has main constituents i.e., 1, 8-cineole, which is eucalyptol (63.81\%), as compared to E. radiata oil, in which the major constituent is limonene (68.51\%). The number of components fluctuates from $44 \%$ to $84 \%$ and these components are mainly responsible for antimicrobial activity (Goldbeck et al., 2014). The essential oils of E. globulus and E. radiata are also equally important; the demands of their essential oils are very high in the market, and they possess antimicrobial, antioxidant, and anti-quorum detecting characteristics (figure 1) (Preethi et al., 2010).

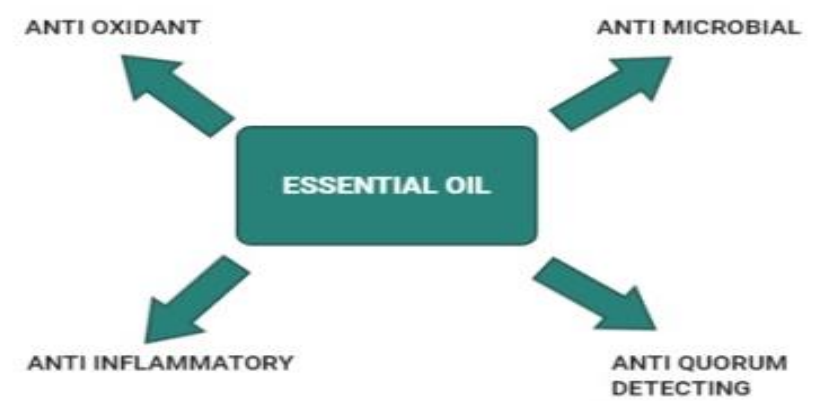

Figure 1: Some characteristics of essential oil

E. citriodora oils are used for pharmaceutical and medicinal purposes. The effect of eucalyptus essential oil against bacteria had been widely observed by agar well diffusion assay in which wells are made in agar plates which are filled by volatile oil and showed the inhibitory effect in the form of zones of inhibition (Kruthi et al., 2014; Adnan, 2019). Eucalyptus oil showed antimicrobial potential against different pathogenic bacterial strains such as $P$. aeruginosa and Staphylococcus aureus (Ishnava et al., 2013). By using high concentration of oil, a greater inhibition zone was observed and by using a low concentration of oil little or less inhibition zone was observed (Tyagi and Malik, 2011). It was found that the inhibitory effect of the eucalyptus oil is more towards Gram-positive bacteria and is less towards Gram-negative bacterial strains (Oussalah et al., 2006). Using agar well diffusion assay, E. globulus oil showed antimicrobial potential against different pathogenic bacterial strains like $P$. aeruginosa and $S$. aureus. It was observed that different concentrations showed different inhibition zones, the larger zone with $100 \%$ concentration of oil was observed. Also, experimentation showed that eucalyptus oil has a higher inhibitory effect against $S$. aureus which is a Gram-positive bacterium compared to $P$. aeruginosa which is Gram-negative bacteria (Adnan, 2019). Mota et al. (2015) showed inhibitory effect of eucalyptus oil against $S$. aureus and Escherichia coli. However, this study showed that the oil had not inhibited Gram-negative bacteria such as Pseudomonas and Salmonella. Kruthi et al. (2014) showed that essential oil of E. globulus was effective against other tested bacterial strains such as $S$. aureus, B. subtilis, E. coli and K. pneumonia. It was found that Gram-negative bacteria were less sensitive compared to Gram-positive ones which showed more inhibitory effect of the oil. Gram-negative bacterial strains were moderately affected by the eucalyptus oil. Another study showed that oil from two species of eucalyptus that is $E$. globulus and E. camaldulensis inhibited bacterial growth at higher concentrations of 5 to 20 microliters when tested against E. coli and S. aureus strains. But it was not effective when used in low concentrations of 1 and 2 microliters. Higher zones of inhibition corresponding to high concentrations were observed (Ghalem et al., 2008). Essential oil of E. camaldulensis has shown antimicrobial activity by agar well diffusion method against a vast range of bacteria like E. coli, S. aureus, S. typhi, $P$. mirabilis and K. pneumonia. Aqueous extract of eucalyptus has shown zones of inhibition towards E. coli $(7 \mathrm{~mm}), K$. pneumonia (9mm), S. typhi $(12 \mathrm{~mm})$, S. aureus $(12 \mathrm{~mm})$ and P. mirabilis $(13 \mathrm{~mm})$. Likewise, acetone extract showed inhibition zones against E. coli $(12 \mathrm{~mm})$ K. pneumonia $(13 \mathrm{~mm})$, S. typhi $(14 \mathrm{~mm})$ P. mirabilis $(15 \mathrm{~mm})$ and $S$. aureus $(14 \mathrm{~mm})$ (Abubakar, 2010)(table 1).

\begin{tabular}{|c|c|c|c|}
\hline Bacteria & $\begin{array}{l}\text { Eucalyptus } \\
\text { camaldulensis }\end{array}$ & Eucalyptus camaldulensis & Reference \\
\hline $\begin{array}{l}\text { Clinical } \\
\text { isolates }\end{array}$ & $\begin{array}{l}\text { Diameter of } \\
\text { zones of } \\
\text { inhibition by } \\
\text { Aqueous } \\
\text { extract }\end{array}$ & $\begin{array}{l}\text { Diameter of zones of } \\
\text { inhibition by Acetone } \\
\text { extract }\end{array}$ & $\begin{array}{l}\text { (Khalaf } \\
\text { and Zahra, } \\
\text { 2020) }\end{array}$ \\
\hline E. coli & $7 \mathrm{~mm}$ & $12 \mathrm{~mm}$ & \\
\hline K. pneumonia & $9 \mathrm{~mm}$ & $13 \mathrm{~mm}$ & \\
\hline S. typhi & $12 \mathrm{~mm}$ & $14 \mathrm{~mm}$ & \\
\hline S. aureus & $12 \mathrm{~mm}$ & $14 \mathrm{~mm}$ & \\
\hline P. mirabilis & $13 \mathrm{~mm}$ & $15 \mathrm{~mm}$ & \\
\hline
\end{tabular}

Table 1: Zone of inhibition (in $\mathrm{mm}$ ) of Eucalyptus aqueous and acetone extract against various pathogen.

Effect of eucalyptus oil on planktonic bacteria: Planktonic bacteria are free-living bacteria that float in liquid media. Effect on the planktonic mode of bacterial growth has been measured by determining minimum inhibitory concentration (MIC). MIC is the lowest amount or concentration of oil that inhibits microbial growth in the case of essential oil used as an antimicrobial agent (Rodriguez-Tudela et al., 2003). It is determined by broth dilution assay in most of the studies and the result is measured in the form of turbidity or optical density (Rodriguez-Tudela et al., 2003). Eucalyptus oil showed effect on different bacterial strains at different concentrations in the form of MIC. Some bacterial isolates like Proteus vulgaris were inhibited when $25 \%$ concentration of oil was used. S. pyogenes and $S$. epidermidis were inhibited at $50 \%$ concentration. $S$. aureus and E. coli was inhibited by the highest concentration of oil i.e. 100\% (Khalaf and Zahra, 2020). Gram-positive bacteria 
had been widely used for testing the efficacy of essential oil. Eucalyptus oil obtained from E. camaldulensis showed moderate effect against $S$. aureus and its MIC ranged from 0.07 to $0.5 \%$. MIC for other bacterial strains like B. subtilis was 0.17 to $0.34 \%$; 0.2 to $0.4 \%$ against $M$. luteus and 0.4 to $1.1 \%$ against S. Pyogenes (Rasooli et al., 2009; Akin et al., 2010; Khubeiz et al., 2016; Knezevic et al., 2016; Reda et al., 2017). Similarly, the MIC values against Gram negative bacterial strains were also observed. Among these the most commonly used bacteria was E. coli for which MIC value ranged from 0.15 to $3.2 \%$. 0.05 to $0.32 \%$ for K. pneumonia (Khubeiz et al., 2016; Ostad Asiaei et al., 2018). A multi drug-resistant bacteria, A. baumannii exhibited MIC value of 0.05 to $0.1 \%$ (Knezevic et al., 2016) and the lowest value of $0.01 \%$ was obtained for the bacterium $V$. parachaemoliticus (Khubeiz et al., 2016) (table 2). Another study revealed the antimicrobial potential of essential oil obtained from E. globulus. The oil proved to be effective against all the strains tested with the lowest activity of $3.13 \mathrm{mg} / \mathrm{ml}$ for $P$. aeruginosa and $S$. infantis. The highest activity of oil was observed against $S$. aureus, $S$. pyogenes and $E$. coli with MIC of $0.09 \mathrm{mg} / \mathrm{mL}$ (Damjanović-Vratnica et al., 2011).

\begin{tabular}{|c|c|c|}
\hline Bacterial strains & $\begin{array}{c}\text { MIC values } \\
\text { as } \%\end{array}$ & References \\
\hline \multicolumn{2}{|c|}{ Gram positive bacteria } & \multirow{6}{*}{$\begin{array}{l}\text { (Rasooli et al., 2009; Akin et al., } \\
\text { 2010; Knezevic et al., 2016; } \\
\text { Reda et al., 2017; Ostad Asiaei et } \\
\text { al., 2018) }\end{array}$} \\
\hline S. aureus & $0.07-0.5$ & \\
\hline B. sub & 0.17 & \\
\hline M. luteus & $0.2-0.4$ & \\
\hline S. pyogenes & $0.4-1.1$ & \\
\hline Gram negat & & \\
\hline E. coli & 011 & 2016; Ostad \\
\hline K. pne & 0.0 & Asiaei et al., 2018) \\
\hline A. baumannii & $0.05-0.1$ & (Knezevic et al., 2016) \\
\hline V. parachaemoliticus & 0.01 & (Khubeiz et al., 2016) \\
\hline
\end{tabular}

Table 2: MIC values of eucalyptus oil against different bacteria

Antibiofilm activity of eucalyptus essential oil: Recently, it was observed that among biofilm-forming bacteria, some bacteria form strong biofilms like E. coli while other form moderate biofilms like $S$. aureus. The essential oil of $E$. camaldulensis had shown inhibition against these biofilms at different concentrations. Results of the study showing the effect of eucalyptus volatile oil against biofilms showed that $S$. epidermidis was inhibited by all concentrations of the oil $(72 \%$, $74 \%$, and $76 \%$ ). Similarly, the bacteria, K. pneumoniae, E. coli and $P$. vulgaris also showed inhibition at all concentrations but in the case of $E$. coli, the highest inhibition was observed at final concentration (97\%) of the oil (Khalaf and Zahra, 2020). In the above-discussed experiment, the oil was applied before the formation of biofilm and had shown a positive effect in inhibition of biofilm formation. Another study done on $P$. aeruginosa confirmed that the oil from $E$. camaldulensis has an antibacterial effect against its biofilm. In this experiment, the oil was used alone and in combination with ciprofloxacin against the bacterial biofilm. The results showed that oil inhibited both planktonic and biofilm when used alone and also have a synergistic effect when used in combination with ciprofloxacin. These experimental observations were obtained by determining MIC, BIC (biofilm inhibitory concentration), and checkerboard assays of oil and antibiotics against bacteria. Checkerboard assays were done by preparing serial dilution of oils and antibiotics whereas BIC was determined by using serially diluted volatile oil in 48 well plates (Al-Qaysi et al.,
2020). The experimentation on oral Streptococci showed that eucalyptus oil has an inhibitory effect on Streptococci biofilm. A strong inhibitory effect on biofilm was observed against seven samples out of total of 10 bacterial samples. Reduction in the biofilm of most oral Streptococci was also observed in concentration-dependent way of oil. However, few Streptococci strains were observed to stimulate biofilm formation (Bahjat, 2019). Research on anti-biofilm activity of eucalyptus oil from E. globulus against $P$. aeruginosa and $S$. aureus showed that essential oil from this plant had a strong inhibitory effect against these bacteria and may also affect other Gram positive and negative bacteria in similar manner. It was observed that both biofilm producers and non-biofilm producers were sensitive to eucalyptus oil. $65.43 \%$ sensitivity by P. aeruginosa biofilm producers and $80.32 \%$ sensitivity by non-biofilm producer strains of $P$. aeruginosa was observed. In case of $S$. aureus, the sensitivity by biofilm producers was $54.16 \%$ and that form on biofilm producers was $68.75 \%$. Biofilm of the latter had shown a high degree of sensitivity (Sambyal et al., 2017). The anti-biofilm activity of essential oil from eucalyptus species against P.mirabilis, which is a urinary tract pathogen also showed $90 \%$ inhibition of the biofilm formation by this bacteria (Mathur and Gutte, 2013).

Effect of lemongrass oil against bacteria: Lemongrass is widely used as an antibacterial and antifungal agent ${ }^{6}$. It has proved to be effective against a diverse range of bacteria including Streptococcus and Pseudomonas species; these bacteria are responsible for food poisoning, lungs, and skin diseases (Cimanga et al., 2002). It has also been found to be effective against fungi and is used in a large number of antifungal skin products as an active ingredient. The antimicrobial properties of lemongrass oil mainly depend on three components which are geranial, neral, and myrcene. Geranial and neral are effective against a vast range of Grampositive and Gram-negative bacteria when used individually or in combination (Akhila, 2009). On the other hand, myrcene is a weak antimicrobial agent showing moderate inhibitory activity (Vadlapudi and Naidu, 2009). Antimicrobial activity of essential oil of three lemongrass species i.e., Pragati, Praman, and Suvarna were tested against Gram-positive bacteria $(S$. aureus and B. subtilis) and Gram-negative bacteria (E. coli and $P$. aeruginosa). The powerful antimicrobial effects were showed by essential oil obtained from Suvarna. These three distinct essential oils showed effective antimicrobial action towards all microbes except for B. subtilis. Likewise, S. aureus was found to be more inhibited by use of these essential oils (Kumar et al., 2016). Much of the research has shown the effect of active ingredients of lemongrass oil alone and in combination with other essential oils to be more effective against Gram-positive bacteria than Gram-negative bacteria (Mith et al., 2014). Lemongrass essential oil was tested against $S$. aureus, $B$. cereus, B. subtilis, E. coli, K. pneumonia and P. aeruginosa (Naik et al., 2010). All of the bacteria were susceptible to various concentrations of lemongrass essential oil except for $P$. aeruginosa which did not respond to any of the tested concentrations even the pure one. This indicates the effectiveness of essential oils against a large bacterial population that is responsible for a wide variety of diseases (Premathilake et al., 2018). Lemongrass essential oil was also found to be effective against bacteria related to food poisonings 
such as Listeria monocytogenes and Salmonella typhimurium as reported by Reis-Teixeira et al. (2019). This proves its potential candidate for food preservation while not compromising the quality and nutrition of the food. Various studies on 1400 bacterial and fungal isolates were tested for their susceptibility to lemongrass oil and around $40 \%$ of the species were effectively eliminated using lemongrass oil at different concentrations (Singh et al., 2017).

Antibiofilm activity of lemongrass oil: Diseases that were previously very easy to treat with antibiotics are no longer responding to even high doses giving rise to multidrug-resistant bacteria (MDR) bacteria. Those bacteria have acquired antibiotic-resistant genes that make antibiotics completely ineffective. Some bacteria, however, in addition to acquiring antibiotic resistance have developed other strategies such as aggregation of bacteria in a protective coating or biofilms (Watnick and Kolter, 2000). These biofilms protect the bacteria from a range of biotic and abiotic factors rendering most of the treatments ineffective against them. Among the many advantages of biofilms is their ability to make the colony of the bacteria more resistant to typical bactericidal agents such as antibiotics, chlorine, and detergents. That is because of the exopolysaccharide, which bacteria secrete in biofilm mode (Watnick and Kolter, 2000). Most chronic infectious diseases in humans such as pneumonia and other life-threatening diseases are caused by Streptococci. P. aeruginosa forms biofilms and causes lung infections in patients suffering from cystic fibrosis. Essential oils of lemongrass have components that can break this biofilm protective covering and interferes with the molecular mechanisms of bacteria thus reducing their ability to reproduce and disrupting their cytoplasm (Brooker and Kleinig, 2004). Essential oil from lemongrass has proved to be an effective treatment for such biofilms forming bacteria.

The combined effect of eucalyptus and lemongrass oils: Lemongrass and eucalyptus in combination possess remarkable strength against different bacteria and diseases. Ghalem and Mohamed (Ghalem et al., 2008) observed great inhibitory activity by both oils against Gram-positive bacteria $B$. subtilis and $K$. pneumonia and a moderate effect on Gram-negative bacteria $E$. coli and $S$. aureus. Combination of eucalyptus and lemongrass in 1:1 express a high inhibitory effect towards $B$. subtilis and $K$. pneumonia and less inhibitory effect towards $E$. coli and S. aureus (Alma et al., 2004). Essential oils extracted from lemongrass and eucalyptus is used traditionally for the cure of typhoid fever and malaria. In the treatment of diseases like stomach ache and typhoid fever, a mixture of leaves and grass of both plants were found to be effective (Kakarla and Ganjewala, 2009). There has been so much research on the antimicrobial potential of lemongrass and eucalyptus against different bacterial and fungal diseases in the eastern medicine system (Mohamed and Ibrahim, 2007). Some authors also suggested the use of these oils as an anti-inflammatory agent because of their ability to modify the immune response in localized areas (Akin-Osanaiye et al., 2007; Dabur et al., 2007). Thus these oils have a special place in traditional herbal medicine. More research is needed to effectively manipulate the true potential of these oils as bactericidal agents without inducing resistance in bacteria and fungi (Jafari et al., 2012).

Mode of action of eucalyptus and lemongrass oils: Lemongrass and eucalyptus oils are composed of many components and their antibacterial activity depends on the site of the attack on bacteria. Both plant oils attack on different sites depending on the lipophilicity of constituents of the oil. Thus, lipophilicity performs an important function in antibacterial activity by penetrating the lipid layer of the cell of bacteria, and due to this penetration mitochondria cause's cell to lose its structural organization (Burt, 2004). Oil components first bind with the surface of the bacterial cell wall causing it to swell and then disrupts the membrane of cytoplasm and cell shrink in response to oil components. The disruption in the structural organization of cytoplasm occurs more than cell walls. Thus, a major component of the bacterial cell that is affected by oil is cytoplasm (Aiemsaard et al., 2011) figure 2.

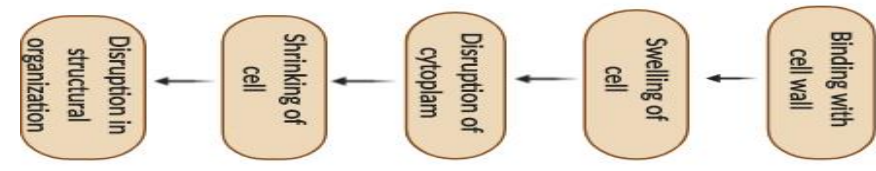

Figure 2: Steps of mode of action of essential oil.

CONCLUSION: Essential oils of lemongrass and eucalyptus are reported to have a promising effect against Gram-positive bacteria compared to Gram-negative bacteria. The combination of both oils has proven inhibitory effect against a vast range of microbial strains either Gram-positive or Gram-negative bacteria in planktonic mode and biofilm mode. The antimicrobial action of the oil mainly depends on its chemical constituents. Essential oil components show antimicrobial activity by disrupting the structural organization of cells of bacteria mainly by destroying cytoplasm. Therefore, they can be used to overcome the problem of bacterial resistance which is due to the repetitive use of antibiotics. Thus, these oils can be a good and natural replacement for different drugs and medicines. Further study is needed to combine oils with other herbal plants extracts and oils, antimicrobial drugs, and products to determine their synergistic effect with those compounds. Such studies will be beneficial in developing new drugs and medicines that will flourish the area of medicine and pharmaceutics. Research efforts must be directed toward detailed mechanism understanding. Detail studies will reduce the problems related to antibiotics, reducing the burden on the healthcare system, and aversion of the antibiotic apocalypse. Furthermore, studies on herbal compounds and oils can cause pharmaceutical industries to develop different drugs from natural products.

ACKNOWLEDGEMENT: No funding was received for this study. CONFLICT OF INTEREST: The authors declare no conflict of interest.

REFERENCES: Abubakar, E.-M. S., 2010. Antibacterial potential of crude leaf extracts of Eucalyptus camaldulensis against some pathogenic bacteria. African journal of plant science 4(6): 202-209.

Adnan, M.. P., 2019. Bioactive potential of essential oil extracted from the leaves of eucalyptus globulus (myrtaceae). Phytochemistry. 8(1): 213-216.

Aiemsaard, J., S. Aiumlamai, C. Aromdee, S. Taweechaisupapong and W. J. R. i. v. s. Khunkitti, 2011. The effect of lemongrass oil and its major components on clinical isolate mastitis pathogens and their mechanisms of action on staphylococcus aureus dmst 4745. Research in veterinary science 91(3): e31e37. 
Akhila, A., 2009. Essential oil-bearing grasses: The genus cymbopogon. CRC press.

Akin-Osanaiye, B., A. Agbaji and M. J. J. o. M. S. Dakare, 2007. Antimicrobial activity of oils and extracts of cymbopogon citratus(lemon grass), eucalyptus citriodora and eucalyptus camaldulensis. Journal of medical sciences 7(4): 777-780.

Akin, M., A. Aktumsek and A. J. Nostro, 2010. Antibacterial activity and composition of the essential oils of Eucalyptus camaldulensis Dehn. And Myrtus communis L. Growing in northern cyprus. African journal of biotechnology 9(4): 11-15

Al-Qaysi, K., M. T. Al-Ouqaili and S. R. Al-Meani, 2020. Ciprofloxacin-and gentamicin-mediated inhibition of Pseudomonas aeruginosa biofilms is enhanced when combined the volatile oil from eucalyptus camaldulensis. Systematic reviews in pharmacy 11(7): 98-105.

Alma, M. H., S. Nitz, H. Kollmannsberger, M. Digrak, F. T. Efe, N. J. Yilmaz. 2004. Chemical composition and antimicrobial activity of the essential oils from the gum of turkish pistachio (Pistacia vera L.). Journal of agricultural and food chemistry 52(12): 3911-3914.

Babayi, H., I. Kolo, J. Okogun and U. Ijah, 2004. The antimicrobial activities of methanolic extracts of eucalyptus camaldulensis and terminalia catappa against some pathogenic microorganisms.

Bachir, R. G. and M. J. A. P. j. o. t. b. Benali, 2012. Antibacterial activity of the essential oils from the leaves of eucalyptus globulus against escherichia coli and staphylococcus aureus. 2(9): 739-742.

Bahjat, S. A. J. R. S., 2019. Evaluation of antibacterial and antibiofilm activity of cinnamon, clove, eucalyptus, and tea tree oils against oral streptococci. 28(3): 1-14.

Boyanova, L., G. Gergova, R. Nikolov, S. Derejian, E. Lazarova, N. Katsarov, I. Mitov and Z. J. m. Krastev, 2005. Activity of bulgarian propolis against 94 helicobacter pylori strains in vitro by agar-well diffusion, agar dilution and disc diffusion methods. 54(5): 481-483.

Brooker, I. and D. Kleinig, 2004. Field guide to eucalypts: Northern australia: Volume three. Bloomings Books.

Burt, S. J., 2004. Essential oils: Their antibacterial properties and potential applications in foods-a review. 94(3): 223253.

Chaves, T. P., F. H. A. Fernandes, C. P. Santana, J. S. Santos, F. D. Medeiros, D. C. Felismino, V. L. Santos, R. M. R. Catão, H. D. M. Coutinho and A. C. Medeiros, 2016. Evaluation of the interaction between the Poincianella pyramidalis (Tul.) lp queiroz extract and antimicrobials using biological and analytical models. 11(5): e0155532.

Cimanga, K., K. Kambu, L. Tona, S. Apers, T. De Bruyne, N. Hermans, J. Totté, L. Pieters and A. J. Vlietinck, 2002. Correlation between chemical composition and antibacterial activity of essential oils of some aromatic medicinal plants growing in the democratic republic of congo. 79(2): 213-220.

Cristo, J. S., E. F. Matias, F. G. Figueredo, J. F. Santos, N. L. Pereira, J. G. Junior, P. E. Aquino, M. N. Nogueira, J. Ribeiro-Filho, F. A. J. I. Cunha and products, 2016. Hplc profile and antibioticmodifying activity of Azadirachta indica A. Juss, (meliaceae). 94: 903-908.

Dabur, R., A. Gupta, T. Mandal, D. D. Singh, V. Bajpai, A. Gurav, G. J.T. Lavekar, Complementary and A. Medicines, 2007.
Antimicrobial activity of some indian medicinal plants. 4(3): 313-318.

Damjanović-Vratnica, B., T. Đakov, D. Šuković and J. S. Damjanović, 2011. Antimicrobial effect of essential oil isolated from eucalyptus globulus labill. From montenegro. 29(3): 277-284.

Ghalem, B. R., B. Mohamed and pharmacology, 2008. Antibacterial activity of leaf essential oils of Eucalyptus globulus and eucalyptus camaldulensis. 2(10): 211-215.

Goldbeck, J. C., J. E. Do Nascimento, R. G. Jacob, Â. M. Fiorentini, W.C. Da Silva and Products, 2014. Bioactivity of essential oils from eucalyptus globulus and eucalyptus urograndis against planktonic cells and biofilms of streptococcus mutans. 60: 304-309.

Ishnava, K. B., J. B. Chauhan and M. B. J. S. j. o. b. s. Barad, 2013. Anticariogenic and phytochemical evaluation of eucalyptus globules labill. 20(1): 69-74.

Jafari, B., A. Ebadi, B. M. Aghdam, Z. J. A.-E. J. A. Hassanzade and E. Sci, 2012. Antibacterial activities of lemon grass methanol extract and essence on pathogenic bacteria. 2: 1042-1046.

Kakarla, S. and D. J. M. A. P. S. B. Ganjewala, 2009. Antimicrobial activity of essential oils of four lemongrass (Cymbopogon flexuosus steud) varieties. 3(1): 107-109.

Kavanaugh, N. L., K. A. Ribbeck and e. microbiology, 2012. Selected antimicrobial essential oils eradicate Pseudomonas spp. and Staphylococcus aureus biofilms. 78(11): 4057-4061.

Khalaf, Z. Z. and L. A.. Zahra, 2020. Evaluation of the activity of essential oil and hydrosol from eucalyptus camaldulensis against some bacterial species. 1282-1288.

Khubeiz, M. J., G. Mansour, R. Zahraa and Research, 2016. Chemical compositions and antimicrobial activity of leaves eucalyptus camaldulensis essential oils from four Syrian samples. 7(5): 251-257.

Knezevic, P., V. Aleksic, N. Simin, E. Svircev, A. Petrovic and N. J. J. Mimica-Dukic, 2016. Antimicrobial activity of eucalyptus camaldulensis essential oils and their interactions with conventional antimicrobial agents against multi-drug resistant acinetobacter baumannii. 178: 125-136.

Kruthi, B. S., K. Srikari, P. SaiPriya, G. S. Ch Jyothi and R. Publication, 2014. In vitro testing of antimicrobial properties of lemongrass, eucalyptus and their synergistic effect. 4(2): 18.

Kumar, G. A., R. Muhury and D. Ganjewala, 2016. A study on antimicrobial activities of essential oils of different cultivars of lemongrass (Cymbopogon flexuosus).

Lokhande, P., K. Gawai, K. Kodam, B. Kuchekar, A. Chabukswar and S. P. Jagdale, 2007. Antibacterial activity of isolated constituents and extract of roots of inula racemosa. 1(1): 712.

Mathur, S. and M. Gutte, 2013. Study the effect of essential oils on microbial biofilm formation by klebsiella pneumonia.

Mith, H., R. Dure, V. Delcenserie, A. Zhiri, G. Daube, A. J. Clinquart and nutrition, 2014. Antimicrobial activities of commercial essential oils and their components against food-borne pathogens and food spoilage bacteria. 2(4): 403-416.

Mohamed, G. A. and S. R. J. A. Ibrahim, 2007. Eucalyptone g, a new phloroglucinol derivative and other constituents from eucalyptus globulus labill. 15: 281-291.

Moosavy, M.-H. and N. J. P. s. Shavisi, 2013. Determination of 
antimicrobial effects of nisin and mentha spicata essential oil against escherichia coli o157: H7 under various conditions (pH, temperature and Nacl concentration). 19(2): 61-67.

Morais-Braga, M. F. B., D. L. Sales, F. dos Santos Silva, T. P. Chaves, V. d. C. N. Bitu, W. M. T. Avilez, J. Ribeiro-Filho and H. D. M. Coutinho, 2016. Psidium guajava l. And psidium brownianum mart ex dc. Potentiate the effect of antibiotics against gram-positive and gram-negative bacteria. 8(5): 683687.

Mota, V. d. S., R. N. T. Turrini and V. Poveda, 2015. Antimicrobial activity of eucalyptus globulus oil, xylitol and papain: A pilot study. 49(2): 0216-0220.

Mulyaningsih, S., F. Sporer, J. Reichling and M. Wink, 2011. Antibacterial activity of essential oils from eucalyptus and of selected components against multidrug-resistant bacterial pathogens. 49(9): 893-899.

Naik, M. I., B. A. Fomda, E. Jaykumar and J. M. Bhat, 2010. Antibacterial activity of lemongrass (cymbopogon citratus) oil against some selected pathogenic bacterias. 3(7): 535-538.

Oloyede, 0., 2009. Chemical profile and antimicrobial activity of cymbopogon citratus leaves. 2: 98-103.

Ostad Asiaei, E., E. Moghimipour and M.. Fakoor, 2018. Evaluation of antimicrobial activity of eucalyptus camaldulensis essential oil against the growth of drugresistant bacteria. 13(4).

Oussalah, M., S. Caillet and M.. Lacroix, 2006. Mechanism of action of spanish oregano, chinese cinnamon, and savory essential oils against cell membranes and walls of escherichia coli o157: H7 and listeria monocytogenes. 69(5): 1046-1055.

Preethi, R., V. V. Devanathan and M. J. Loganathan, 2010. Antimicrobial and antioxidant efficacy of some medicinal plants against food borne pathogens. 4(2): 122-125.

Premathilake, U., D. Wathugala and R.. Dharmadasa, Med. Aromatic Plants, 2018. Evaluation of chemical composition and assessment of antimicrobial activities of essential oil of lemongrass (cymbopogon citratus (dc.) stapf). 4: 13-19.

Rasooli, I., S. Shayegh and S.. Astaneh, 2009. The effect of mentha spicata and eucalyptus camaldulensis essential oils on dental biofilm. 7(3): 196-203.

Rauber, C. d. S., S. S. Guterres, E.. Schapoval and B. Analysis, 2005. Lc determination of citral in cymbopogon citratus volatile oil. 37(3): 597-601.
Reda, F. M., Y. El-Zawahry, A. S. Omar and Biotechnology, 2017. Synergistic effect of combined antibiotic and methanol extract of eucalyptus camaldulensis leaf against staphylococcus aureus and pseudomonas aeruginosa. 5(4): 486-497.

Reis-Teixeira, F. B., I. P. Sousa, V. F. Alves, N.. Furtado and E. C. P. J. De Martinis, 2019. Evaluation of lemongrass and ginger essential oils to inhibit listeria monocytogenes in biofilms. 39(4): e12627.

Rodriguez-Tudela, J., F. Barchiesi, J. Bille, E. Chryssanthou, M. Cuenca-Estrella, D. Denning, J. Donnelly, B. Dupont, W. Fegeler, C. J. C. M. Moore and Infection, 2003. Method for the determination of minimum inhibitory concentration (mic) by broth dilution of fermentative yeasts. 9(8): i-viii.

Sambyal, S. S., P. Sharma, D.C. M. Shrivastava and A. Sciences, 2017. Anti-biofilm activity of selected plant essential oils against pseudomonas aeruginosa and staphylococcus aureus. 6(3): 444-450.

Santin, M. R., A. O. dos Santos, C. V. Nakamura, B. P. Dias Filho, I. C. P. Ferreira and T. J. Ueda-Nakamura, 2009. In vitro activity of the essential oil of cymbopogon citratus and its major component (citral) on leishmania amazonensis. 105(6): 14891496.

Silva, J., W. Abebe, S. Sousa, V. Duarte, M. Machado and F. Matos, 2003. Analgesic and anti-inflammatory effects of essential oils of eucalyptus. 89(2-3): 277-283.

Singh, S., S. K. Singh, I. Chowdhury and R. Singh, 2017. Understanding the mechanism of bacterial biofilms resistance to antimicrobial agents. 11: 53.

Thwaites, G. E., J. D. Edgeworth, E. Gkrania-Klotsas, A. Kirby, R. Tilley, M. E. Török, S. Walker, H. F. Wertheim, P. Wilson and M. J. Llewelyn, 2011. Clinical management of staphylococcus aureus bacteraemia. 11(3): 208-222.

Tyagi, A. K. and A.. Malik, 2011. Antimicrobial potential and chemical composition of eucalyptus globulus oil in liquid and vapour phase against food spoilage microorganisms. 126(1): 228-235.

Vadlapudi, V. and K. C. Naidu, 2009. In vitro bioefficiency of marine mangrove plant activity of rhizophora conjugata. 1: 1598-1600.

Watnick, P. and R. J. Kolter, 2000. Biofilm, city of microbes. 182(10): 2675-2679.

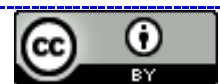

Except where otherwise noted, this item's licence is described as (C) The Author(s) 2021. Open Access.

This item is licensed under a Creative Commons Attribution 4.0 International License, which permits use, sharing, adaptation, distribution and reproduction in any medium or format, as long as you give appropriate credit to the original author(s) and the source, provide a link to the Creative Commons license, and indicate if changes were made. The images or other third party material in this it are included in the article's Creative Commons license, unless indicated otherwise in a credit line to the material. If material is not included in the article's Creative Commons license and your intended use is not permitted by statutory regulation or exceeds the permitted use, you will need to obtain permission directly from the copyright holder. 